\title{
PERVAPORATION APPLIED FOR DEWATERING OF REACTION MIXTURE DURING ESTERIFICATION
}

\author{
Andrzej Krasiński ${ }^{*}$, Patrycja Wierzba ${ }^{1}$, Agata Grudzień ${ }^{1}$, Halina Hajmowicz ${ }^{2}$, \\ Krzysztof Zawada ${ }^{2}$, Ludwik Synoradzki ${ }^{2}$ \\ ${ }^{1}$ Warsaw University of Technology, Faculty of Chemical and Process Engineering, Waryńskiego 1, \\ 00-645 Warsaw, Poland \\ ${ }^{2}$ Warsaw University of Technology, Faculty of Chemistry, ul. Noakowskiego 3, 00-664 Warsaw, \\ Poland
}

\section{Dedicated to Prof. Ryszard Pohorecki on the occasion of his 80th birthday}

In this work the esterification of diethyl tartrate was studied. The research was focused on the enhancement of reversible reaction yield, which is accomplished by dewatering of the reaction mixture. The removal of water shifts the equilibrium towards the main product. Pervaporation was applied for this purpose, and results were compared to distillation. The advantages and limitations of both processes are discussed. The experimental part consists of dewatering of mixture after the reaction had reached the equilibrium, and was subsequently fed to the test rig equipped with a single zeolite membrane purchased from Pervatech B.V. Results show a significant conversion increase as a result of water removal by pervaporation. Compared to distillation no addition of organics is necessary to efficiently remove water above the azeotrope. Nevertheless, some limitations and issues which call for optimisation are pointed out. A simple numerical model is proposed to support design and sizing of the pervaporation system. Various modes of integrated system operation are also briefly discussed.

Keywords: diethyl tartrate, esterification, pervaporation, distillation, integrated process

\section{INTRODUCTION}

Carboxylic esters are commonly synthesised through reversible reaction of carboxylic acids with alcohols yielding ester and water as side products. Esterification is a reaction limited by a thermodynamic equilibrium. In order to enhance the reaction yield and move the equilibrium to the product side, a large excess of one of the reactants (in general, alcohol) should be used or a byproduct (typically water) can be selectively removed from the reaction mixture. The reaction is rather slow but its rate can be increased by addition of strong acids (e.g. sulfuric acid, dry hydrogen chloride, methanesulfonic acid or toluenesulfonic acid) or solid ion-exchange resins (e.g. Dowex ${ }^{\circledR}$, Amberlyst ${ }^{\mathbb{R}}$, Amberjet ${ }^{\circledR}$ ).

Tartaric acid derivatives are important components of many industrially relevant processes, in particular used in pharmaceutical sector. This popularity arises from the structure which despite its small mass and simplicity contains four functional groups and two stereogenic centers. Esters of tartaric acid are widely used as chiral building blocks in constructions of active pharmaceutical ingredients (API) (Kim et al. 1997; Le et al., 2013; Takahashi et al. 2012) and polymers (Dhamaniya et al. 2011; Mathakiyaa et al. 2004), as chiral catalysts, ligands and auxiliary compounds for a variety of organic 
synthesis reactions (He et al. 2014; Li et al.; 2014; Yang et al. 2014). Quite often tartaric acid derivatives are used as separation agents in the form of chiral auxiliaries, derivatising agents or components of stationary phase in chromatographic columns. In 2001 Karl Barry Sharpless was awarded the Nobel prize for achievements in catalytic asymmetric oxidation methods. In his research diethyl tartrate (DET) was used as an auxiliary chiral component of the process.

The reversible esterification of tartaric acid with ethanol runs in two reversible stages as presented in Fig. 1. The equilibrium constants for the first and second stage of the reaction at $80^{\circ} \mathrm{C}$ are $K_{l}=8.06$ and $K_{2}=1.31$, respectively (Nemec et al., 2005).

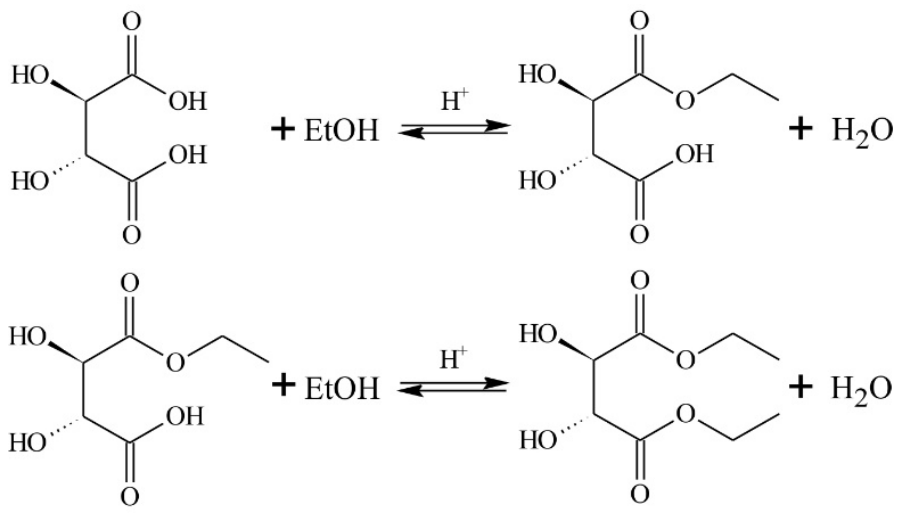

Fig. 1. Chemistry of diethyl tartrate synthesis

Due to the fact that separation of DET from remains of unreacted acid is not easy, it is important to carry out the process with high conversion. To increase the reaction yield various methods of dehydration are used industrially and can be applied for synthesis of DET. Traditional approaches such as the distillation of azeotropic mixture or application of water adsorbents bring substantial costs to the process. Pervaporation is a separation method suitable for water removal and gaining a great importance in the chemical industry. The process involves selective transport from the liquid feed mixture through a membrane with simultaneous vaporisation. The gaseous permeate is subsequently condensed or swept with an inert gas thus providing the driving force for the pervaporation process, i.e. difference of partial pressure of the preferentially transported component (Bowen et al., 2004). The main advantage of pervaporation is possibility to separate mixtures forming azeotropes such as ethanolwater, isopropanol-water, n-butanol-water as well as systems containing close-boiling liquids or thermally sensitive compounds. This is due to separation mechanism, which is almost independent of the vapour-liquid equilibrium (unlike distillation), therefore process can be conducted at a usually lower temperature determined by the reaction kinetics as well as activation energy for pervaporation. Moreover, no addition of chemicals is needed to dope the feed mixture as in the case of extractive distillation, thus there is no contamination and a secondary separation process is not required. The selectivity and flux are determined by the difference in sorption and diffusion through the membrane (Wee et al., 2008). The membrane is a barrier between the two phases, the liquid phase - feed, and the vapour phase - permeate. There are different types of membranes used for pervaporation including polymeric, ceramic and composite membranes (Chapman et al., 2008; Liu et al., 2007; Shao et al., 2007). However, due to an excellent chemical resistance and thermal stability, ceramic membranes are of the interest in recent years. An example of ceramic membrane is zeolite which forms a crystalline structure with uniform size of pores corresponding to a kinetic diameter of molecules. Zeolite NaAtype membranes due to their hydrophilic properties arising from the silicon dioxide to alumina ratio in the range of 2.0-6.8 (Pera-Titus, 2008) are widely used for the dehydration of alcohols or other solvents. Pervaporation is considered as an effective and low energy consuming technology used in "difficult" separation processes competitive to conventional separation technologies such as distillation, extraction or adsorption. Recently, numerous cost analyses to compare various separation techniques were carried out for ethanol dehydration (Cardona Alzate et al., 2006; Cardona et al., 2007; Kaminski 
et al., 2008). Results show that pervaporation is a competitive technology in terms of relatively low total operating costs which directly results from a lower energy consumption and the fact that no additives are required. On the other hand the investment costs for pervaporation units are generally higher than those for distillation due to the complexity of the process and high membrane costs (Kunnakorn et al., 2013).

The current application of pervaporation includes solvents and volatile organic dehydration, removal of organic compounds from water, organic/organic separation, but it also can be used for integrated esterification and dehydration (so-called pervaporation membrane reactor). In literature, several applications of pervaporation process to dewatering of different reaction mixtures have been reported, e.g. acetic acid and isopropanol (Sanz et al., 2006), acetic acid and ethanol (De la Iglesia et al., 2007), acrylic acid and n-butanol (Sert et al., 2014), oleic acid and ethanol (Kumar et al., 2011), propionic acid and isopropanol (Rathod et al., 2014), tartaric acid and ethanol (Keurentjes et al., 1994).

In this work synthesis of diethyl tartrate is studied. The process was performed in two following stages: (i) reaction of tartaric acid with ethanol until reaching the equilibrium, and (ii) dewatering of reaction mixture by pervaporation to move the reaction forward and in consequence decrease the concentration of tartaric acid in the feed mixture.

\section{MATERIALS AND METHODS}

\subsection{Reaction mixture}

DET ester was synthetised by the reaction of tartaric acid (TA) ( $750 \mathrm{~g}, 5$ moles), with ethanol (3 litres, 51 moles) at $75-80^{\circ} \mathrm{C}$. Two types of catalysis were studied:

1. homogeneous, using sulphuric acid added to the reaction mixture $(0.25 \mathrm{~g}, 0.0025$ mole, $0.5 \%$ mole of catalyst per TA),

2. heterogeneous, using the Amberlyst 15 ( $97.5 \mathrm{~g}, 0.13 \mathrm{~g} / \mathrm{g}$ of catalyst per TA).

The process was carried out in a 5-litre heated vessel (reaction mixture of $3117 \mathrm{~g}$ ) equipped with a condenser. The mass fraction of DET in the mixture at the equilibrium state determined using GC was $79 \%$ (excluding water and ethanol). This corresponds to $76.25 \%$ yield of the theoretical DET formation, i.e. molar ratio of DET (product) to initial amount of TA (substrate).

Since pervaporation membrane used in the process is limited to $\mathrm{pH} \geq 2$ and temperatures less than $150^{\circ} \mathrm{C}$ the operating conditions were selected to comply with these constrains. The reaction mixtures used for pervaporation experiments are characterised in Table 1.

Table 1. Composition of reaction mixtures at the start of pervaporation experiments; initial ratio of substrates $\mathrm{EtOH} / \mathrm{TA}=10 \mathrm{~mol} / \mathrm{mol}$, temperature of the reaction $75-80^{\circ} \mathrm{C}$

\begin{tabular}{|c|c|c|c|c|c|c|c|}
\hline \multirow{2}{*}{$\begin{array}{c}\text { Catalyst } \\
\text { type }\end{array}$} & \multirow{2}{*}{$\begin{array}{c}\text { Catalyst to } \\
\text { TA ratio }\end{array}$} & \multicolumn{5}{|c|}{$\begin{array}{c}\text { Composition of reaction mixture, \%mas. } \\
\text { (calculated equilibrium concentrations in the bracket) }\end{array}$} \\
\cline { 4 - 8 } & & EtOH & TA & $\mathrm{H}_{2} \mathrm{O}$ & MET & DET \\
\hline \multirow{2}{*}{$\mathrm{I}$} & $\mathrm{H}_{2} \mathrm{SO}_{4}$ & $0.5 \% \mathrm{~mol}$ & $\begin{array}{c}62.1 \\
(63.6)\end{array}$ & $\begin{array}{c}0.0729 \\
(0.0869)\end{array}$ & $\begin{array}{c}5.20 \\
(5.25)\end{array}$ & $\begin{array}{c}6.77 \\
(4.66)\end{array}$ & $\begin{array}{c}25.8 \\
(26.4)\end{array}$ \\
\hline $\mathrm{II}$ & \multirow{2}{*}{ Amberlyst } & $0.13 \mathrm{~g} / \mathrm{g}$ & $\begin{array}{c}62.3 \\
(62.1)\end{array}$ & $\begin{array}{c}0.169 \\
(0.0975)\end{array}$ & $\begin{array}{c}5.10 \\
(5.32)\end{array}$ & $\begin{array}{c}7.30 \\
(5.03)\end{array}$ & $\begin{array}{c}25.1 \\
(27.4)\end{array}$ \\
\hline
\end{tabular}


The reaction mixtures were subsequently poured into the feed tank of the pervaporation system. As water was removed through the membrane, the equilibrium of the reaction was moved towards the DET formation and the reaction continued. The main difference was that in the case of heterogeneous catalysis, the reaction was no longer catalysed during dewatering. However, in the case of homogeneous catalysis sulphuric acid was present in the feed mixture, and catalysed the reaction during pervaporation.

The reference for pervaporation is the reaction enhancement by a typical azeotropic distillation with addition of cyclohexane. In the latter case, the process was performed in a 1-litre vessel equipped with a packed distillation column with the height of $600 \mathrm{~mm}$ and diameter of $30 \mathrm{~mm}$ with an electromagnetic valve to control the reflux. $4 \mathrm{~mm}$ Raschig rings were used as the packing.

\subsection{Experimental setup}

The experiments were carried out in a test rig for pervaporation process in a batch mode as presented in Fig. 2.

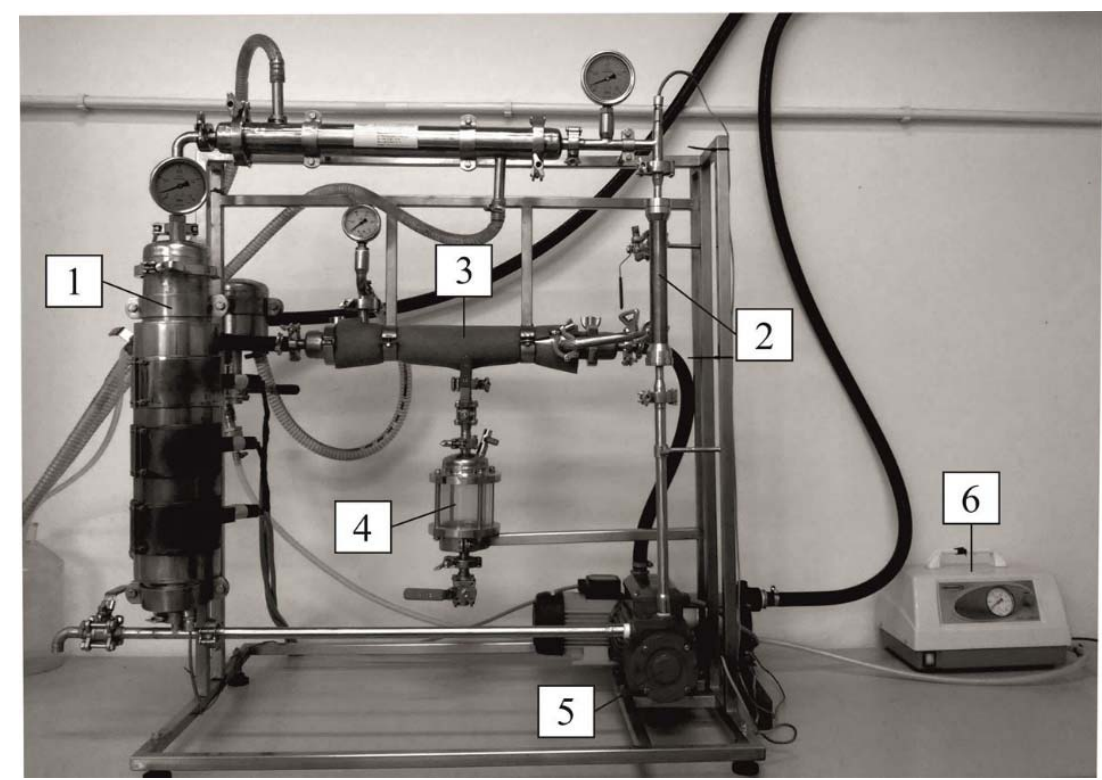

Fig. 2. The photograph of the test rig used in experiments;

1-feed tank, 2-pervaporation module, 3- permeate condenser, 4-permeate collection tank, 5-circulation pump, 6-vacuum pump

The reaction mixture containing water was poured into the feed tank equipped with a heating jacket. The temperature of the feed was controlled and set to $80^{\circ} \mathrm{C}$. The process was performed in a closed loop: the liquid was circulated by the peripheral pump from the feed tank then passed through the pervaporation module and back to the tank. The pervaporation unit was fitted with a single tubular membrane supplied from Pervatech B.V. The dimensions of the membrane tube were as follows: the total length $250 \mathrm{~mm}$, inner and outer diameters $7 \mathrm{~mm}$ and $10 \mathrm{~mm}$, respectively. The membrane support was anisotropic ceramic tube made of two types of alumina, outside $\alpha-\mathrm{Al}_{2} \mathrm{O}_{3}$ layer and thin inner layer of $\gamma-\mathrm{Al}_{2} \mathrm{O}_{3}$. The selective layer was an organic-inorganic hybrid and silica-based material, prepared by sol-gel process using bis-silyl precursors, such as bis(triethoxysilyl)ethane (BTESE) and bis(triethoxysilyl)methane (BTESM) (Veen et al., 2011). The selective layer of the membrane was located on the inner surface of the ceramic support, hence the feed mixture passed through the module through the lumen. On the outer side vacuum (approx. 30 mbar) was applied to achieve the driving force for the permeation process. Vapours which passed through the membrane were condensed in a "shell and tube" heat exchanger and drained into the collection vessel. To guarantee reasonable 
hydrodynamic conditions and avoid the detrimental effect of the concentration polarisation on the permeate flux a linear velocity of about $3 \mathrm{~m} / \mathrm{s}$ through the membrane tube was applied. The process performance parameters such as the permeate flux, the selectivity of separation and the advancement of esterification reaction (referred to the equilibrium) was determined based on following measurements:

- water concentration in the feed mixture - every 3 hours,

- total mass and water concentration in the permeate - every 3 hours provided a sufficient amount was collected,

- $\quad$ composition of the feed - once per day (every 6-8 hours).

The water concentration in the feed was determined by coulometric Karl Fischer method, while in the permeate using a refractometer. The composition of the reaction mixture (i.e. feed) was analyzed using a HP 6890 gas chromatograph equipped with a HP-1 column $(30 \mathrm{~m} \times 0.32 \mathrm{~mm} \times 0.25 \mu \mathrm{m})$ and FID detector. Prior to analysis $50 \mathrm{mg}$ samples were silylated with BSA $(0.5 \mathrm{~mL})$ and heated in an oven at $50{ }^{\circ} \mathrm{C}$ for $1 \mathrm{~h}$. Conditions of analysis: initial temperature $100^{\circ} \mathrm{C}$, heating rate $10{ }^{\circ} \mathrm{C} / \mathrm{min}$ to $320^{\circ} \mathrm{C}$, isotherm $10{ }^{\circ} \mathrm{C}$, injector temperature $250^{\circ} \mathrm{C}$, carrier gas: air $400 \mathrm{~mL} / \mathrm{min}$, hydrogen $40 \mathrm{~mL} / \mathrm{min}$, helium $1.2 \mathrm{~mL} / \mathrm{min}$.

\subsection{Model formulation}

In the batch mode of operation selective transport takes place as the feed mixture circulates from the tank through the membrane module. The total mass contained in the feed tank and the circulation loop is decreased due to the permeation as well as the concentration of the preferentially transported component is reduced (provided the transport through the membrane is selective). This can be described by the mass balance equation for a differential time interval $d t$ :

$$
d M=-J A d t
$$

The mass balance for a preferentially permeating component can be expressed as:

$$
d(M x)=-J y A d t
$$

Expanding term on the LHS of Eq. (2), and combining it with Eq. (1), one can obtain following formulae for a non-reacting system:

$$
d x=\frac{(x-y) J A}{M} d t
$$

The transient values of $M$ can be obtained by integration of equation (1):

$$
M=M_{0}-\int_{0}^{t} J A d t
$$

where $M_{0}$ is an initial mass of the feed mixture. The main problem is to determine correctly local value of the permeate flux, which depends on feed composition and temperature. As permeation proceeds the composition of the feed mixture entering the module decreases. The decrease of the concentration occurs along the module, and this affects the local driving force for the transport. In addition, the temperature in the tank and isolated circulation lines is kept constant, but in the module the heat for evaporation is withdrawn from the feed mixture, which also brings about a decrease of the permeation rate. Therefore, for further considerations the tubular module needs to be discretised into cylindrical volumes of the length $d z$ along the flow direction as proposed by Baig (2008) and presented in Fig. 3.

The total mass of the feed mixture decreases as a result of pervaporation in the circulation loop through the membrane module. Selective permeation reduces water concentration, but in the case of reactive mixture water still can be produced in the feed mixture due to the esterification reaction advancement. 
To account for this effect the component mass balance must be supplied with kinetic data of the reaction. Accordingly, the energy balance should include enthalpy of the reaction.

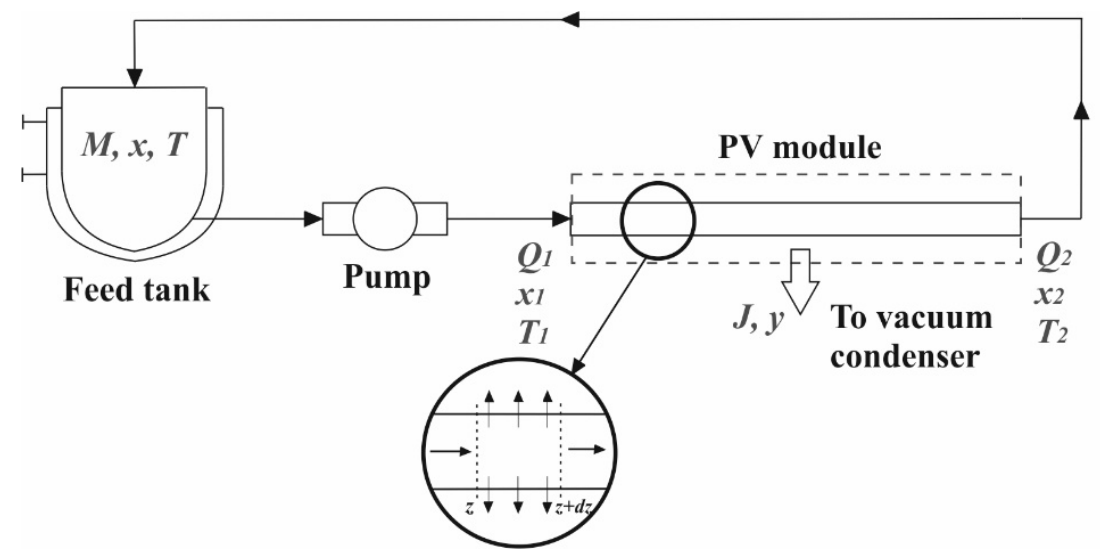

Fig. 3. Sketch of the circulation loop of the feed mixture in the batch process and the discretisation scheme for the tubular membrane

Balances of the total mass, compound and energy for the differential volume (or permeation surface) inside a single pervaporation module can be written as follows:

$$
\begin{gathered}
d Q=-J \pi D d z \\
d(Q x)=-J y \pi D d z+R \\
d(Q h)=-J \Delta h_{p} \pi D d z+R \Delta h_{r}
\end{gathered}
$$

where $Q$ and $J$ represent local values of feed flow rate and permeate flux, respectively. Combining Eqs. (5) with (6) and (7) one can obtain:

$$
\begin{aligned}
& d x=\frac{(x-y) J \pi D}{Q} d z \\
& d T=-\frac{\Delta h_{p} J \pi D}{Q c_{p}} d z
\end{aligned}
$$

and the local value of the flow rate at position $z$ in the module can be expressed as:

$$
Q=Q_{0}-\pi D \int_{0}^{z} J d z
$$

where $Q_{0}$ denotes the flow rate of the feed mixture entering the membrane module.

In modelling of the pervaporation process the main problem is determination of the permeate flux and its composition (related to the selectivity of separation), which depend on process conditions. These parameters are influenced by membrane properties as well as feed temperature and composition.

$$
\begin{aligned}
& J=f_{1}(T, x) \\
& y=f_{2}(T, x)
\end{aligned}
$$

In this work separation parameters were determined by fitting them to experimental data, and functions $f_{1}$ and $f_{2}$ were established. Substituting these functions into Eqs. (8-10), changes of flowrate, feed composition and temperature in $z$ direction can be calculated. To find a numerical solution, discretisation into finite lengths $\Delta z$ is applied for the membrane module, and also the process time is 
discretised into $\Delta t$ to account for the effect of changing the composition of the reaction mixture and the feed with time in a closed loop batch process. The perfect mixing is assumed for the feed tank, which is vigorously agitated by the liquid circulation. In addition, both the reaction and permeation are very slow, and depending on operating conditions they can be considered as the steps limiting the overall process rate.

\section{RESULTS AND DISCUSSION}

Pervaporation process with chemical reaction studied in this work was compared to the azeotropic distillation performed in the system described in Section 2.2. The distillate was collected at the temperature of three-component azeotrope equal to $62^{\circ} \mathrm{C}$, and subsequently separated as a heterophasic mixture. The light cyclohexane phase (74\% wt. of distillate) contained $98-99.7 \%$ of cyclohexane and approx. $0.15 \%$ of water, while the heavy aqueous phase (26\% wt. of distillate) contained $83 \%$ of ethanol. After 80 hours diethyl tartrate esterification reached $97.9 \%$ yield.

When switching to pervaporation, the first step was dewatering of a binary mixture of ethanol and water using the hydrophilic zeolite membrane. Results are presented in Fig. 4.

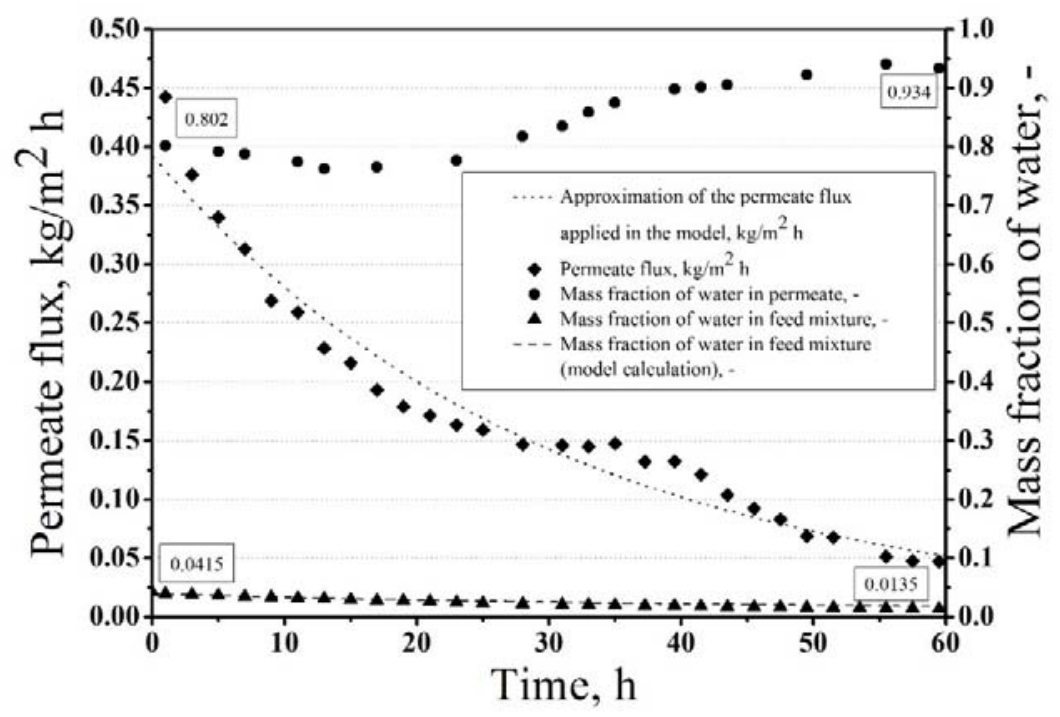

Fig. 4. Permeate flux and concentration of water in feed and permeate during the process

An experiment with an addition of appropriate amount of sulfuric acid to binary ethanol-water mixture was carried out to confirm the negligible effect of homogeneous catalyst on the process performance. Prior to experiment it was verified that the applied concentration of acid would not cause a decrease of $\mathrm{pH}$ below 2 (the limit of membrane stability). No significant differences were observed for both mixtures in terms of permeate flux and selectivity of separation. However, the activity of preferentially transported compound could potentially be different during esterification, and to verify this an experiment with a real reaction mixture without a catalyst was carried out as a best approximation of the permeate flux for the pervaporation model with an accompanying reaction. Again the flux and selectivity were very similar to the results obtained from previous experiments with the pure ethanolwater mixture and with addition of homogeneous catalyst. Neither acid nor esters were passing through the membrane, only water and ethanol were condensed and collected as the permeate. Therefore, an approximation of the permeate flux obtained for binary ethanol-water mixture was applied in the numerical model, including an integrated process with a simultaneous chemical reaction.

The results of dewatering of reaction mixture showing the time evolution of the concentration of tartaric acid, esters and water are presented in Fig. 5. 


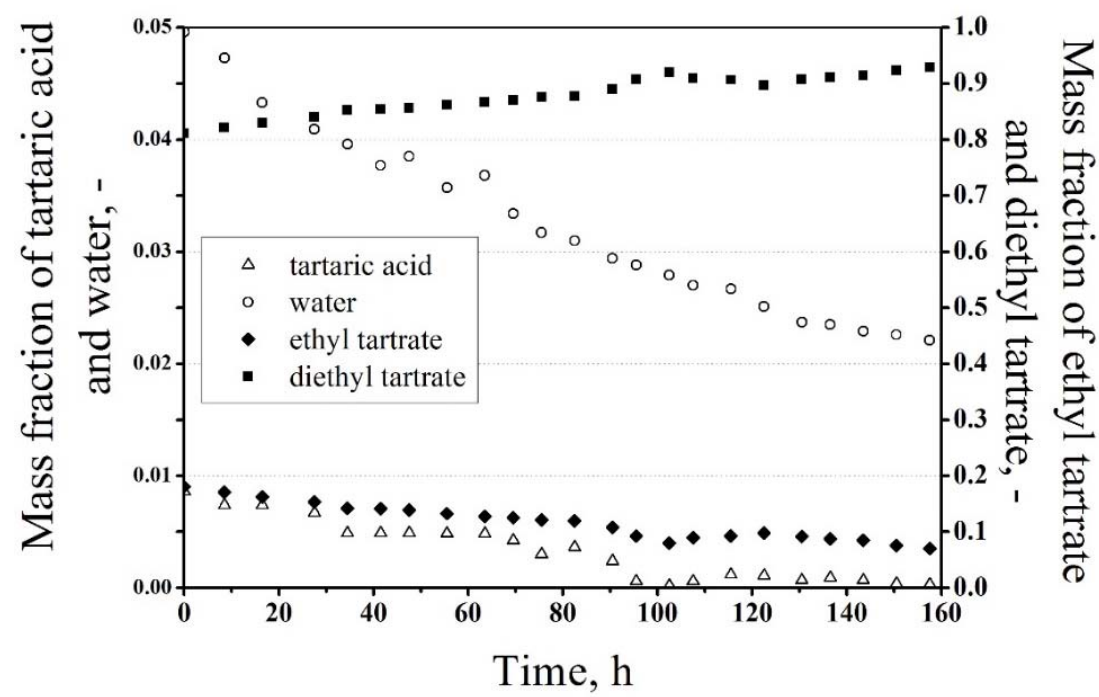

Fig. 5. Concentration of reactants during pervaporation with reaction

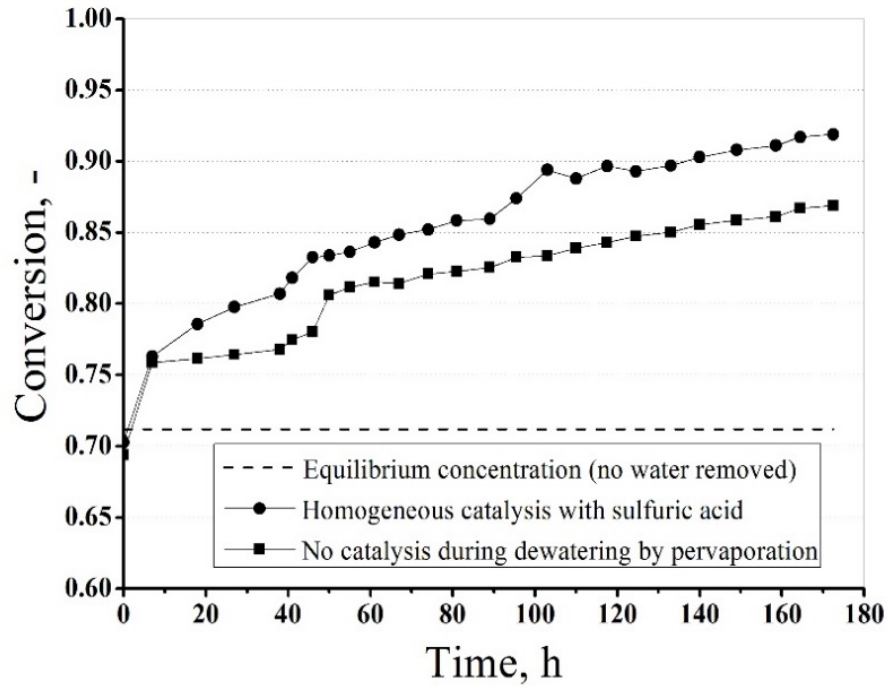

Fig. 6. Enhancement of esterification reaction by dewatering, with and without catalysis

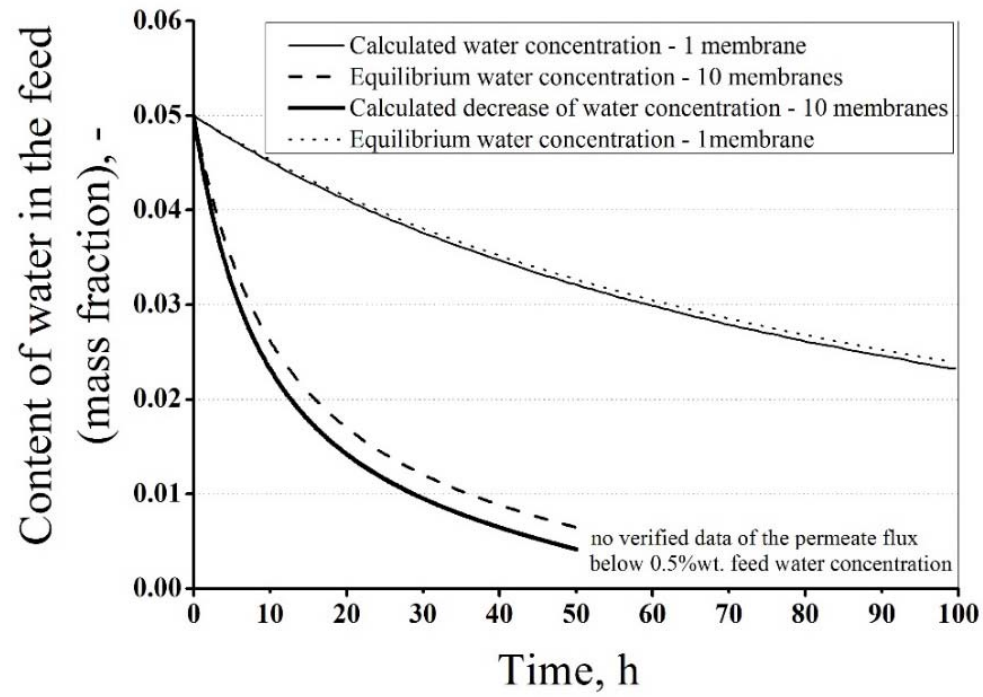

Fig. 7. Calculated profiles of water concentration decrease during pervaporation and chemical reaction; initial conditions: $M_{0}=2 \mathrm{~kg}, x_{0}=0.05$ 
Water removal moves the reaction equilibrium towards ester formation, thus brings about a reduction of the tartaric acid concentration to zero, which means that the substrate is fully depleted due to the esterification. As water is removed ethyl ester is converted into diethyl ester. The remaining amount of monoethyl ester is still significant, even when the concentration of tartaric acid approaches zero. To reach $100 \%$ of the conversion into DET a very "deep" dewatering of the reaction mixture is necessary.

It is critical that in an integrated process the reaction advancement must be enhanced by catalysis. Homogeneous catalysis brings no operational problems provided the membrane is not detrimentally affected by acid. However, heterogeneous catalysis requires circulation of the reaction mixture between the PV unit and the reactor. Various configurations can be used such as in-series, parallel or membrane units integrated with granular catalyst grains. These issues are carefully studied and discussed in literature (Nemec et al., 2005). However, when no catalysis is applied during pervaporation, the reaction yield is strongly reduced as presented in Fig. 6, where conversion is defined as the molar ratio of diethyl tartrate (DET) formed during esterification to the initial amount of tartaric acid (TA).

In Fig. 7 the influence of membrane surface on the process performance is presented. The increase of membrane modules (mounted in parallel) accelerates dewatering. For a single membrane the concentration of water in the feed almost overlaps with calculated equilibrium concentrations. This means that the process is limited by the rate of transport of water through the membrane. However, when a module equipped with ten membranes is used there is a gap between the transient concentration and equilibrium one, which means that the slow reaction limits the overall process rate.

\section{CONCLUSIONS}

In this work the application of pervaporation to enhance the yield of diethyl tartrate esterification is presented. A commercial hydrophilic zeolite membrane purchased from Pervatech was used. Results confirm that pervaporation can be considered as a competitive alternative to an extractive distillation. The latter one is a good technique in terms of separation efficiency, although three-component azeotrope contains only $4.3 \%$ of water, which means simultaneous distillation of large amounts of ethanol (87\%) from the reaction mixture (high energy consumption), and the need for its regeneration. The addition of a toxic organic compound such as cyclohexane is avoided during pervaporation, which is of high importance for obtaining high purity products, e.g. for pharmaceutical use. Both techniques enable removal of water from the reaction mixture, and move its equilibrium towards the main product (DET). When pervaporation was applied the tartaric acid concentration decreased to zero, which means a complete depletion of the substrate due to the formation of esters. The loss of ethanol was relatively low due to its concentration approximately between $7-20 \%$ in the permeate (surprisingly the lower limit corresponded to lower water content in the feed mixture). If necessary, ethanol can be potentially regained from the permeate by pervaporation using an organophilic membrane. However, the obtained rate of water removal (i.e. permeate flux) for pervaporation was low, which for a single tubular module made the entire process relatively slow. It took almost a week to decrease the water concentration in the reaction mixture from around $5 \%$ to below $0.5 \%$ for a $3.75 \mathrm{~kg}$ batch. Thus, a scale-up of the pervaporation system must be considered.

The experimental part provided data which were included in the model to determine the process rate when the membrane surface area is increased. A numerical simulation can also enable to determine the moment of transition from the diffusion limited process to the kinetic regime (i.e. limited by chemical reaction), thus support the sizing of membrane area and calculate the process time depending on the batch volume.

Another issue related to the process arises from relatively low solubility and high viscosity of tartaric acid in ethanol. This is an important design factor for the circulation loop of pervaporation, but should 
also be carefully considered when the integrated process with a heterogeneous catalysis in flow through the packed bed is applied.

We are grateful to the National Centre for Research and Development, Poland for founding this research within the framework of the project „CHIKADI” PBS2/A1/14/2014.

\section{SYMBOLS}

\begin{tabular}{|c|c|}
\hline$A$ & total membrane area, $\mathrm{m}^{2}$ \\
\hline$c_{p}$ & specific heat of feed mixture, $\mathrm{J} \mathrm{kg}^{-1} \mathrm{~K}^{-1}$ \\
\hline$D$ & membrane diameter (inner), $\mathrm{m}$ \\
\hline$h$ & enthalpy of the feed, $\mathrm{J} \mathrm{kg}^{-1}$ \\
\hline$J$ & mass flux of the permeate, $\mathrm{kg} \mathrm{m}^{-2} \mathrm{~s}^{-1}$ \\
\hline$K_{i}$ & equilibrium constants of reaction (for $\mathrm{i}=1$ or 2 ), - \\
\hline$M$ & mass of the feed, $\mathrm{kg}$ \\
\hline$Q$ & mass flowrate of the feed, $\mathrm{kg} \mathrm{s}^{-1}$ \\
\hline$R$ & reaction rate, $\mathrm{kg} \mathrm{m}^{-3} \mathrm{~s}^{-1}$ \\
\hline$t$ & time, $\mathrm{s}$ \\
\hline$T$ & temperature, $\mathrm{K}$ \\
\hline 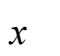 & mass fraction of transported component in the feed, \\
\hline
\end{tabular}

\section{REFERENCES}

Baig F.U., 2008. Pervaporation, In: Li N.N., Fane A.G., Winston Ho W.S., Matsuura T. (Eds.), Advanced Membrane Technology and Applications. John Wiley \& Sons, 469-488. DOI: 10.1002/9780470276280.ch17.

Bowen T.C., Noble R.D., Falconer J.L., 2004. Fundamentals and applications of pervaporation through zeolite membranes. J. Membr. Sci., 245, 1-33. DOI: 10.1016/j.memsci.2004.06.059.

Cardona Alzate C.A., Sanchez Toro O.J., 2006. Energy consumption analysis of integrated flowsheets for production of fuel ethanol from lignocellulosic biomass. Energy, 31, 2447-2459. DOI: $10.1016 /$ j.energy.2005.10.020.

Cardona C.A., Sanchez O.J., 2007. Fuel ethanol production: Process design trends and integration opportunities. Bioresour. Technol., 98, 2415-2457. DOI: 10.1016/j.biortech.2007.01.002.

Chapman P.D., Oliveira T., Livingston A.G., Li K., 2008. Membranes for the dehydration of solvents by pervaporation. J. Membr. Sci., 318, 5-37. DOI: 10.1016/j.memsci.2008.02.061.

De la Iglesia O., Mallada R., Menendez M., Coronas J., 2007. Continuous zeolite membrane reactor for esterification of ethanol and acetic acid. Chem. Eng. J., 131, 35-39. DOI: 10.1016/j.cej.2006.12.015.

Dhamaniya S., Jacob J., 2012. Synthesis and characterization of copolyesters based on tartaric acid derivatives. Polym. Bull., 68, 1287-1304. DOI: 10.1007/s00289-011-0606-9.

He S, Wei Y., Meng X., 2014. CN 103739592.

Kamiński W., Marszałek J., Ciołkowska A., 2008. Renewable energy source - Dehydrated ethanol. Chem. Eng. J., 135, 95-102. DOI: 10.1016/j.cej.2007.03.017.

Keurentjes J.T.F., Janssen G.H.R., Gorissen J.J., 1994. The esterification of tartaric acid with ethanol: Kinetics and shifting the equilibrium by means of pervaporation. Chem. Eng. Sci., 49, 4681-468. DOI: 10.1016/S00092509(05)80051-X.

Kim C.U., Lew W., Williams M.A., Liu H., Zhang L., Swaminathan S., Bischofberger N., Chen M.S., Mendel D.B., Tai C.Y., Laver W.G., Stevens R.C., 1997. Influenza neuraminidase inhibitors possessing a novel hydrophobic interaction in the enzyme active site: Design, synthesis, and structural analysis of carbocyclic sialic acid analogues with potent anti-influenza activity. J. Am. Chem. Soc., 119, 681-690. DOI: 10.1021/ja963036t.

Kumar K.S., Satyanarayana S.V., 2011. Studies of a pervaporation membrane batch reactor. Asia-Pac. J. Chem. Eng., 6, 575-580. DOI: 10.1002/apj.431. 
Kunnakorn D., Rirksomboon T., Siemanond K., Aungkavattana P., Kuanchertchoo N., Chuntanalerg P., Hemra K., Kulprathipanja S., James R.B., Wongkasemjit S., 2013. Techno-economic comparison of energy usage between azeotropic distillation and hybrid system for water-ethanol separation. Renew. Energ., 51, 310-316. DOI: 10.1016/j.renene.2012.09.055.

Li J., Ma Z., Zhou F., Huang L., 2013. Faming Zhuanli Shenqing. CN 103351372.

Li W., Tao Ch., Xiang L., Luo J., Peng Ch., 2014. CN 103664888.

Liu Y.-L., Yu C.-H., Lee K.-R., Lai J.-Y., 2007. Chitosan/poly(tetrafluoroethylene) composite membranes using in pervaporation dehydration processes. J. Membr. Sci., 287, 230-236. DOI: 10.1016/j.memsci.2006.10.040.

Mathakiyaa I.A., Rakshita A.K., Iyerb D.B., Shahb A.K., 2004. Novel biodegradable polyamides based on tartaric acid: Preparation and properties. Int. J. Polym. Mater. 53, 405-418. DOI: 10.1080/00914030490429915.

Nemec D., van Gemert R., 2005. Performing Esterification reactions by combining heterogeneous catalysis and pervaporation in a batch process. Ind. Eng. Chem. Res., 44, 9718-9726. DOI: 10.1021/ie050283.

Pera-Titus M., 2008. Preparation of inner-side tubular zeolite NaA membranes in a continuous flow system. Sep. Purif. Technol., 59, 141-150. DOI: 10.1016/j.seppur.2007.05.038.

Rathod A.P., Wasewar K.L., Kyoo Yoo C., 2014. Enhancement of esterification of propionic acid with isopropyl alcohol by pervaporation reactor. J. Chem., 2014, 1-4. DOI: 10.1155/2014/539341.

Sanz M.T., Gmehling J., 2006. Esterification of acetic acid with isopropanol coupled with pervaporation. Part II. Study of a pervaporation reactor. Chem. Eng. J., 123, 9-14. DOI: 10.1016/j.cej.2006.06.011.

Sert E., Atalay F.S., 2014. N-Butyl acrylate production by esterification of acrylic acid with n-butanol combined with pervaporation. Chem. Eng. Process., 81, 41-47. DOI: 10.1016/j.cep.2014.04.010.

Shao P., Huang R.Y.M., 2007. Polymeric membrane pervaporation. J. Membr. Sci., 287, 162-179. DOI: 10.1016/j.memsci.2006.10.043.

Takahashi M., Murata Y., Hakamata Y., Suzuki K., Sengoku T., Yoda H., 2012. First total synthesis and absolute stereochemical assignment of vittarilide-A, an antioxidant extractive component isolated from Vittaria angusteelongata Hayata. Tetrahedron, 38, 7997-8002. DOI: 10.1016/j.tet.2012.06.105.

van Veen H.M., Rietkerk M.D.A., Shanahan D.P., van Tuel M.M.A., Kreiter R., Castricum H.L., ten Elshof J.E., Vente J.F., 2011. Pushing membrane stability boundaries with HybSi ${ }^{\circledR}$ pervaporation membranes. J. Membr. Sci., 380, 124-131. DOI: 10.1016/j.memsci.2011.06.040.

Wee S., Tye C., Bhatia S., 2008. Membrane separation process - Pervaporation through zeolite membrane. Sep. Purif. Technol., 63, 500-516. DOI: 10.1016/j.seppur.2008.07.010.

Wynn N., 2000. Dehydration with silica pervaporation membranes. Sulzer Technical Review, 3, 10-12.

Yang Ch., Qiang J., Wei H., 2014. CN 103804355 A.

Received 30 June 2015

Received in revised form 01 February 2016

Accepted 20 February 2016 